\title{
Subjective and objective knowledge and decisional role preferences in cerebrovascular patients compared to controls
}

This article was published in the following Dove Press journal:

Patient Preference and Adherence

2 August 2016

Number of times this article has been viewed

\author{
Christina Riechel ${ }^{1, *}$ \\ Anna Christina Alegiani 1 ,* \\ Sascha Köpke ${ }^{2}$ \\ Jürgen Kasper ${ }^{3,4}$ \\ Michael Rosenkranz',5 \\ Götz Thomalla' \\ Christoph Heesen ${ }^{1,4}$ \\ 'Department of Neurology, \\ University Medical Center Hamburg- \\ Eppendorf, Hamburg, Germany; \\ ${ }^{2}$ Nursing Research Unit, Institute of \\ Social Medicine and Epidemiology, \\ University of Lübeck, Lübeck, \\ Germany; ${ }^{3}$ Department of Health \\ and Caring Sciences, Faculty of \\ Health Sciences, University of \\ Tromsø, Tromsø, Norway; ${ }^{4}$ Institute \\ of Neuroimmunology and Multiple \\ Sclerosis, University Medical Center \\ Hamburg-Eppendorf, Hamburg, \\ Germany; ${ }^{5}$ Department of Neurology, \\ Albertinen-Krankenhaus, Hamburg, \\ Germany \\ *These authors contributed equally \\ to this work
}

\begin{abstract}
Background: Risk knowledge and active role preferences are important for patient involvement in treatment decision-making and adherence. Although knowledge about stroke warning signs and risk factors has received considerable attention, objective knowledge on secondary prevention and further self-esteem subjective knowledge have rarely been studied. The aim of our study was to investigate knowledge and treatment decisional role preferences in cerebrovascular patients compared to controls.
\end{abstract}

Methods: We performed a survey on subjective and objective stroke risk knowledge and autonomy preferences in cerebrovascular patients from our stroke outpatient clinic $(n=262)$ and from pedestrians on the street taken as controls during a "World Stroke Day" $(n=274)$. The questionnaire includes measures for knowledge and decisional role preferences from previously published questionnaires and newly developed measures, for example, subjective knowledge, revealed on a visual analog scale.

Results: The overall stroke knowledge was low to moderate, with no differences between patients and controls. Knowledge about secondary prevention was particularly low. Only $10 \%-15 \%$ of participants correctly estimated the stroke absolute risk reduction potential of aspirin. The medical data interpretation competence was moderate in both groups. Age and basic mathematical and statistical understanding (numeracy) were the only independent predictors of objective stroke knowledge, whereas previous stroke had no impact on stroke knowledge. However, patients were thought to be better informed than controls. Approximately $60 \%$ of both patients and controls claimed to prefer a shared decision-making approach in treatment decisions.

Conclusion: The level of stroke risk knowledge in patients with cerebrovascular diseases was as low as in randomly selected pedestrians, although patients felt better informed. Both groups preferred involvement in treatment decision-making. We conclude that educational concepts for increasing awareness of knowledge gaps as well as for stroke risk and for prevention strategies are needed.

Keywords: knowledge, decisional role preferences, cerebrovascular patients, stroke

\section{Introduction}

Stroke is the leading cause of acquired permanent disability among adults and the second leading cause of death in Western industrialized nations. ${ }^{1}$ For both patients and relatives, stroke significantly affects quality of life. ${ }^{2}$ Management of acute stroke patients has greatly changed during the last decades. Establishment of dedicated stroke units has markedly improved acute stroke care and has contributed to improved outcomes. ${ }^{3}$ Although contemporary drugs clearly show significant benefits for secondary stroke prevention in randomized controlled trials, adherence 
and implementation in routine care are still a challenge. ${ }^{4}$ It has been postulated that $9 \%$ of all cardiovascular events in Europe could be attributed to poor adherence to vascular medications alone. ${ }^{5}$ Management of lifestyle and risk factors are especially relevant for stroke patients, but show barriers in implementation. ${ }^{6}$

A number of studies have shown that knowledge of stroke warning signs and risk factors for general stroke is at best low to moderate among healthy individuals, people at risk, and after stroke. ${ }^{7,8}$ Very less work has addressed knowledge about secondary stroke prevention, but it has also indicated limited secondary prevention knowledge in stroke survivors. ${ }^{9}$ These studies focused on objective knowledge based on the results of questionnaires. Subjective knowledge of patients, meaning a self-rating item of knowledge, has not been addressed. In addition, there is only scarce information about decisional role preferences in stroke patients, ${ }^{10}$ mostly from trials on atrial fibrillation decision-making. ${ }^{11}$ Decisional role preferences ask for the preferred interaction styles between a patient and a physician from a purely autonomous to a paternalistic attitude regarding medical decisions. Although numerous informative materials for stroke patients already exist, patients claim multiple unmet needs, which might partially refer to the quality of the available information. ${ }^{12}$ In a recent survey, more than $50 \%$ of stroke patients demanded more information about their strokes, for example, about prevention of recurrence. ${ }^{13}$ Characteristics and effects of interventions to improve medication adherence are uncertain, and the full health benefits of medicines are not realized. As a consequence, studies aiming at patient knowledge and medication adherence are needed. ${ }^{14}$

It has been postulated that embedding information provision in a process of shared decision-making is the key to better care, better outcomes, and reduced costs. ${ }^{15}$ Transfer of knowledge to facilitate shared decision-making is necessary and might thereby be a major condition of effective primary and secondary prevention. ${ }^{16}$ Thus, evidence-based patient information is a prerequisite for informed choice and incorporates science and rigor of evidence-based medicine with the personal values of patients. ${ }^{17}$ In neurology, we have found a high percentage of autonomous role preferences among multiple sclerosis (MS) patients compared to those with other diseases. ${ }^{18}$

This study aimed at assessing stroke risk knowledge in patients from a cerebrovascular disease outpatient clinic compared to control pedestrians from the street, focusing on risk factors and secondary prevention and comparing subjective and objective knowledge. Furthermore, we aimed at assessing treatment decisional role preferences in patients and controls. We assumed that patients with a history of cerebrovascular disease would present higher subjective and objective risk knowledge.

\section{Methods}

We surveyed 262 consecutive patients from the cerebrovascular disease outpatient clinic at the Department of Neurology, University Medical Centre Hamburg-Eppendorf between October 2010 and July 2011. Patients present to the cerebrovascular disease outpatient clinic with a cerebrovascular risk profile. Most had suffered a previous stroke. In parallel, an abbreviated questionnaire was presented to 274 randomly selected adult pedestrians, addressed as controls, on the street in the pedestrian area of downtown Hamburg in October 2010 via an information desk during the "World Stroke Day 2010".

Sample size was determined to be $>250$ in each group to achieve representative results, given that we have no previous values to calculate the power. Besides demographic data, information on stroke knowledge regarding symptoms, pathophysiology, treatment, risk factors, and prevention were obtained. The questionnaire consisted of the following parts:

- general questions about stroke symptoms, causes, and treatment (four items);

- risk factors: diabetes, atrial fibrillation (two items);

- secondary prevention: acetylsalicylic acid, blood pressure (two items);

- medical data interpretation (one item);

- self-rated level of stroke knowledge (one item);

- autonomy preferences in stroke prevention decisionmaking (one item); and

- warning signs (nine items). ${ }^{19}$

One index question (numeracy item) from the Medical Data Interpretation Test addressed the capability of comparing risk rates on overall mortality of cancer compared to stroke. ${ }^{20}$ Subjective stroke knowledge was assessed using a self-rating scale of the level of feeling informed about stroke risk. The self-rating scale was obtained using a visual analog scale from 0 to $10(0=$ no subjective knowledge $)$. For analysis, we transferred the visual analog scale to a metric count. Autonomy preferences were assessed with the Control Preference Scale, which asks for five preferred interaction styles from a purely autonomous to a paternalistic attitude, with the shared decision-making approach as an in-between category. ${ }^{21}$ In the "informed choice" model, patients decide but take physicians' opinions into account, whereas in the "professional as agent" model, the physician makes the decision taking the patients opinion into account. Although the scale is a simplification 
of a complex interaction, it is the most commonly applied and studied tool in the field. ${ }^{21}$ The categories were briefly explained to the patient as a statement on each interaction style before they were asked for their preferred decision approach. This approach was applied successfully in a previous work. ${ }^{18}$ We added nine questions from a recently adapted German version of the 16-item Stroke Action Test (STAT) to our questionnaire and administered it to a subgroup (96 out of 296) of the patient cohort. ${ }^{19}$ This instrument included item naming and describing stroke symptoms and has shown good reliability in a sample $(n=195)$ of consecutive stroke patients in a metropolitan region in Germany (Cronbach's $\alpha$ coefficient $>0.9) .{ }^{19}$

Objective stroke knowledge was defined as the sum of correct answers of all questions of knowledge, with the exclusion of the numeracy competence. We used a questionnaire format as in the earlier work. ${ }^{18}$

The final questionnaire tool for patients included 20 questions, six general questions about stroke, three in multiple choice, nine concerning reaction on warning signs, six relating to decisional role preferences, and one as a visual analog scale.

This study is part of a larger project on the development of evidence-based patient information for patients with stroke and is a survey study in healthy individuals and in patients from a neurovascular unit approved by the Ethics committee of the Hamburg Chamber of Physicians and received full support (Approval: PV 4980). As data analysis was performed completely anonymously, and it was considered impractical to provide an additional sheet for people interviews on the stroke day, we obtained oral informed consent.

\section{Statistical analysis}

For data analysis, the statistical program SPSS was used (version 15.0, SPSS Inc., Chicago, IL, USA). Fisher's exact tests were applied to check variations of autonomy preferences between the two study cohorts. For analysis of the impact of different factors on stroke knowledge, univariate and multivariate linear regression analyses were applied. Linear regression analysis was conducted for the target criterion risk knowledge. Simple linear regressions were conducted for each of the six predictors (education, age, sex, autonomy preference, cohort, and numeracy competence). Corrected $r^{2}$ were calculated, indicating the extent to which knowledge could be explained by the particular predictors. Finally, a linear regression equation was calculated using all six predictors simultaneously. Subjective and objective stroke knowledge was compared for the two groups with bivariate Pearson correlation coefficient. The influence of age and sex was partialized out using stepwise regression analyses.

\section{Results}

Two hundred and sixty-two patients and 274 controls were included. Patients were older than controls, and there were more male patients. There were, however, a few controls who had a previous stroke, but the diagnosis of a previous stroke was significantly more frequent in the patient cohort (Table 1).

Questions concerning symptoms (ie, if impaired vision is an acute stroke symptom) and pathophysiology (ie, if ischemic stroke is caused by artery occlusion) were correctly answered by most of the participants $(>90 \%)$. Questions about primary prevention (eg, treatment of diabetes) and secondary prevention (eg, effectiveness of aspirin treatment) revealed low levels of knowledge $(<50 \%)$. Questions about risk factors (eg, cardiac arrhythmias) and knowledge about pathological blood pressure values revealed moderate levels of knowledge $(\sim 50 \%)$. The medical data interpretation item was answered correctly by only $\sim 40 \%$ in both groups. Apart from treatment of diabetes, there were no significant knowledge differences between patients and controls (Table 2).

Study results did not differ when patients with a previous stroke in the control cohort were excluded from the analysis. No additional significant difference was revealed when only patients with previous stroke were compared with controls without previous stroke. Only the better knowledge of patients concerning the stroke risk in diabetes remained significant.

Regression analysis revealed age and numeracy as independent predictors of objective stroke knowledge (Table 3). Education, sex, autonomy preference, group, or previous stroke had no influence on stroke knowledge.

In the patient subcohort $(n=96)$, when the STAT was administered, on average, one-quarter of the patients misclassified the seriousness of possible stroke symptoms (regarding hemiparesis and aphasia, aphasia and paresthesia). ${ }^{19} \mathrm{~A}$ further $50 \%$ of patients misclassified symptoms if they were less obvious (eg, loss of vision in one eye) (for detailed data, see Table S1).

Patients were thought to be better informed than controls (subjective knowledge) even after adjusting for the influence of age and sex, but actual (objective) knowledge was low.

Table I Demographic data

\begin{tabular}{llll}
\hline Demographic data & $\begin{array}{l}\text { Patients } \\
\text { (n=253) }\end{array}$ & $\begin{array}{l}\text { Controls } \\
(\mathbf{n}=\mathbf{2 7 4})\end{array}$ & P-value $^{\text {a }}$ \\
\hline Mean age (years) & $64($ SD II.4) & $57($ SD I5.7) & $<0.00 \mathrm{I}$ \\
Female & $72(27.5 \%)$ & $\mathrm{I} 63(59.5 \%)$ & $<0.00 \mathrm{I}$ \\
History of stroke & $\mathrm{I} 7 \mathrm{I}(67.6 \%)$ & $\mathrm{I} 7(6.2 \%)$ & $<0.00 \mathrm{I}$ \\
\hline
\end{tabular}

Note: aFisher's exact test.

Abbreviation: SD, standard deviation. 
Table 2 Stroke knowledge

\begin{tabular}{|c|c|c|c|}
\hline Stroke knowledge & $\begin{array}{l}\text { Patients } \\
(n=262)\end{array}$ & $\begin{array}{l}\text { Controls } \\
(n=274)\end{array}$ & $P$-value \\
\hline \multicolumn{4}{|l|}{ General stroke knowledge } \\
\hline $\begin{array}{l}\text { Impaired vision is an acute } \\
\text { stroke symptom }\end{array}$ & $220(84 \%)$ & $242(88 \%)$ & 0.168 \\
\hline $\begin{array}{l}\text { Ischemic stroke caused } \\
\text { by artery occlusion }\end{array}$ & $253(97 \%)$ & $265(97 \%)$ & 1.000 \\
\hline Stroke caused by hemorrhage & 190 (73\%) & 203 (74\%) & 0.697 \\
\hline $\begin{array}{l}\text { Emergency call in case of mild } \\
\text { symptoms }\end{array}$ & $208(79 \%)$ & $215(78 \%)$ & 0.833 \\
\hline \multicolumn{4}{|l|}{ Knowledge on stroke risk } \\
\hline $\begin{array}{l}\text { Treatment of diabetes } \\
\text { reduces stroke risk }\end{array}$ & $56(21 \%)$ & $94(34 \%)$ & 0.001 \\
\hline $\begin{array}{l}\text { Effectiveness of aspirin } \\
\text { for prevention }\end{array}$ & $26(10 \%)$ & $4 \mid(15 \%)$ & 0.090 \\
\hline $\begin{array}{l}\text { Cardiac arrhythmias increase } \\
\text { stroke risk }\end{array}$ & $112(43 \%)$ & $122(45 \%)$ & 0.728 \\
\hline $\begin{array}{l}\text { Knowledge about } \\
\text { pathological blood pressure }\end{array}$ & $107(4 \mid \%)$ & $99(36 \%)$ & 0.287 \\
\hline Medical data interpretation & III (42\%) & 117 (43\%) & 0.938 \\
\hline
\end{tabular}

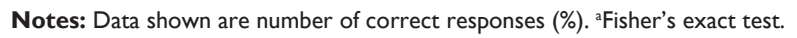

In both groups, subjective knowledge was significantly higher than objective knowledge (Table 4).

With regard to decisional roles, there was a significant difference between patients and controls in the distribution of answers ( $P=0.001)$. Although in both groups, the majority ( $57 \%$ of patients, $64 \%$ of controls) claimed a shared decisionmaking approach in treatment decisions as preferred, patients more frequently favored physician-led decisions (21\%) compared to controls (10\%) (Figure S1). This difference between autonomy preferences of the study groups corresponds with an $r^{2}$ of 0.029 in an ordinal regression analysis. This means that only $3 \%$ of autonomy preferences are explained by the patient's affiliation to study cohorts (Figure 1). After partializing out the influence of sex and age, only a $1 \%$ explained variance remained for cohort affiliation.

Table 3 Univariate and multivariate regression analysis of determinants of stroke knowledge

\begin{tabular}{lll}
\hline Predictor & $\begin{array}{l}\text { Summarized questions of } \\
\text { knowledge }\left(\text { corrected } \boldsymbol{r}^{2}\right)\end{array}$ & P-value $^{\mathbf{a}}$ \\
\hline $\begin{array}{lll}\text { Univariate regressions } \\
\quad \text { Education }\end{array}$ & $0.007(0.002)$ & 0.230 \\
Age & $0.027(0.026)$ & $<0.00$ I \\
Sex & $<0.001(0.002)$ & 0.699 \\
Autonomy preference & $0.004(0.001)$ & 0.202 \\
Study cohort & $<0.001(0.002)$ & 0.699 \\
$\quad$ Numeracy & $0.028(0.027)$ & $<0.00$ I \\
Multivariate regression & & $0.35 \mathrm{I}$ \\
$\quad$ All six predictors & $0.037(0.004)$ & \\
\hline Note: ${ }^{2 A n a l y s i s ~ o f ~ v a r i a n c e . ~}$ & &
\end{tabular}

Table 4 Subjective and objective stroke knowledge

\begin{tabular}{llll}
\hline Stroke knowledge & Patients & Controls & $\boldsymbol{P}_{\text {-value }}$ \\
\hline $\begin{array}{l}\text { Subjective stroke } \\
\text { knowledge }\end{array}$ & $6.3 \pm 2.5$ & $5.2 \pm 2.6$ & $<0.00 \mathrm{I}$ \\
$\begin{array}{l}\text { Objective stroke } \\
\text { knowledge }\end{array}$ & $3.9 \pm 1.0$ & $3.8 \pm 1 . \mathrm{I}$ & 0.107 \\
$R$ & $0.282\left(<0.00 \mathrm{I}^{\mathrm{a}}\right)$ & $0.332\left(<0.00 \mathrm{I}^{\mathrm{a}}\right)$ & \\
\hline
\end{tabular}

Notes: Values are mean $\pm \mathrm{SD}$; $R=$ bivariate Pearson correlation coefficient. anpaired $t$-test

Abbreviation: SD, standard deviation.

\section{Discussion}

As a major finding in this study, knowledge about stroke risk factors and prevention was moderate to low and not higher in cerebrovascular patients compared to controls. Despite the poor knowledge, patients felt better informed than controls.

The lack of stroke knowledge is mirrored in the reaction patterns on warning signs as measured by the STAT questionnaire in the patient cohort. ${ }^{19}$ The necessity to call an ambulance even in case of mild stroke symptoms was not clear for all the patients in this subgroup. Depending on symptoms, $\sim 25 \%-50 \%$ of patients did not consider stroke as a possible origin of symptoms. These data are in line with other studies showing that less than half of the participants would call an ambulance in case of typical stroke symptoms. ${ }^{22}$ Similarly, low knowledge score values were obtained in patients who had undergone carotid endarterectomy ${ }^{23}$ In particular, it seems that increased vascular risk is associated with lower knowledge in patients. ${ }^{24,25}$ This matches our finding of a relevant discrepancy between subjective and objective knowledge.

Numerous studies have shown poor knowledge in stroke patients and in the public. ${ }^{24,26}$ For example, only $50 \%$ of neurological nonstroke patients recognized cerebral artery stenosis as an important cause of stroke, whereas $91 \%$ identified hypertension as a vascular risk factor from a provided list. However, less than $10 \%$ of respondents knew that cardiac arrhythmia is a potential cause of stroke. ${ }^{26}$ Low risk knowledge further leads to medication nonadherence and less primary care by physicians, ${ }^{27}$ which points out the need for knowledge improvement for stroke prevention.

There was a trend toward more knowledge in patients with previous stroke, as study results show a better knowledge regarding the impact of treatment of diabetes on stroke risk. But relevant knowledge on secondary prevention is missing in patients with previous stroke compared to controls without any history of stroke.

Age and numeracy were identified as the only meaningful independent predictors of objective stroke knowledge in our 


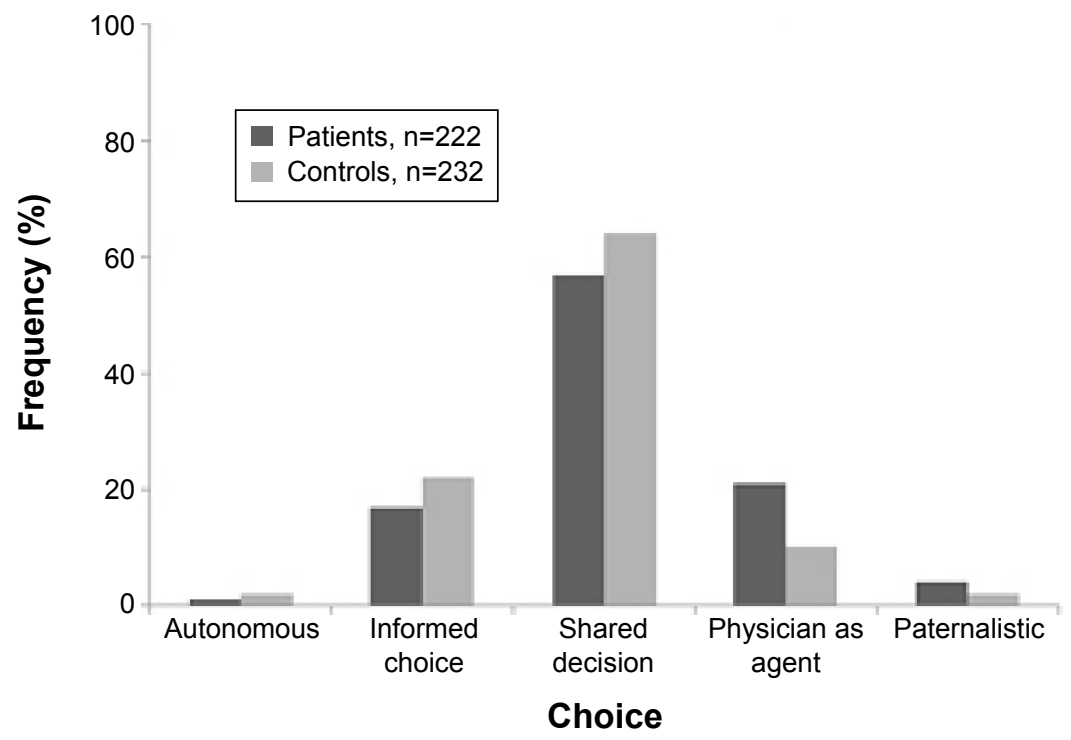

Figure I Frequencies of first choice preferred roles by patients.

study, comparable to previous results. ${ }^{28}$ This underlines the challenge of information provision for aging patients in contrast to other patient groups, for example, those with MS. ${ }^{18}$

Interestingly, patients at the cerebrovascular outpatient department, where two out of three had a history of stroke, were not better informed than controls. But why did patients rate their knowledge higher than controls? Possibly patient self-esteem and coping strategies to handle their lives after a stroke could explain this discrepancy. In addition, the lack of thoroughly processed information in stroke patients might be a result of the fact that most receive new medications in an emergency setting or shortly thereafter without a thorough decision-making process. False estimates about knowledge might be a barrier for further information uptake and behavior change. Further work is needed to better understand these discrepancies.

A recent systematic review stressed substantial unmet patient information needs on secondary prevention, including lifestyle issues such as diet or exercise. ${ }^{12}$ This review also showed that information to some extent improves patient and carer knowledge of stroke, aspects of patient satisfaction, and reduces patient depression scores. A recent trial, however, could not show a consistent effect toward knowledge improvement. ${ }^{29}$ To our knowledge, rigorously developed evidence-based patient information has not been studied in this field. ${ }^{17}$ The overestimation of treatment effects of acetylsalicylic acid in our survey is another strong indicator for the need to improve patient information interventions, especially for effective secondary prevention. In addition, our screening item on medical data interpretation with only $40 \%$ correct answers indicates that these interventions have to be carefully developed and clinically evaluated to make them understandable and helpful for decision-making. ${ }^{30}$ Recently, educational interventions including self-monitoring and decision aids for the treatment of atrial fibrillation have been systematically reviewed. ${ }^{31}$ The primary end point time in the therapeutic range of an anticoagulant was not significantly improved by interventions. Interestingly, decisional conflict was enhanced even in educated patients. However, our work in MS shows that educated patients make more informed choices and might even show improved adherence. ${ }^{32} \mathrm{We}$ hypothesize that this approach is also possible in stroke. The strong preference of patients and controls to be actively involved in medical decision-making emphasizes this goal, although patients declared lower levels of autonomy preferences than controls did.

There were imbalances with regard to sex and age between the groups, and we had no information about the level of education. However, explained variance by the group affiliation was $1 \%$ after considering the influence of age and sex, which were not equally distributed in the groups, thereby indicating that the difference is not clinically meaningful. Due to missing data, we do not have much information about the risk profile of the cohorts. But, significantly more patients had a history of previous stroke (nearly $70 \%$ ), in contrast to controls $(\sim 6 \%)$. Incomplete data about the risk profile were also based on the aim to make a distribution to controls on the street feasible. Finally, only a subgroup of the patients received the STAT questionnaire, which limits generalization of the results for the whole sample. ${ }^{19}$ 


\section{Conclusion}

Our data show a low level of risk knowledge among cerebrovascular outpatient clinic patients associated with a wrongly perceived high subjective knowledge level. However, patients claimed the need for involvement in decision-making. The lack of knowledge combined with an active role preference calls for more systematic approaches to enhance knowledge and participation in decision-making in cerebrovascular patients. Validated, evidence-based stroke patient information might have the potential to close the gap between the substantial knowledge about stroke prevention derived from controlled trials and the implementation into long-term clinical care. However, these information strategies need rigorous evaluation following the framework of studying complex interventions. As a consequence, this approach might positively impact treatment adherence for secondary prevention, which needs further studying.

\section{Disclosure}

The authors report no conflicts of interest in this work.

\section{References}

1. Heuschmann PU, Busse O, Wagner M, et al. Schlaganfallhäufigkeit und Versorgung von Schlaganfallpatienten in Deutschland [Frequency and Care of Stroke in Germany]. Aktuel Neurol. 2010;(37):333-340. German.

2. Dennis M, O'Rourke S, Lewis S, Sharpe M, Warlow C. A quantitative study of the emotional outcome of people caring for stroke survivors. Stroke. 1998;29(9):1867-1872.

3. Stroke Unit Trialists' Collaboration. Organised inpatient (stroke unit) care for stroke. Cochrane Database Syst Rev. 2013;9:CD000197.

4. Bushnell CD, Zimmer LO, Pan W, et al. Persistence with stroke prevention medications 3 months after hospitalization. Arch Neurol. 2010;67(12): $1456-1463$.

5. Chowdhury R, Khan H, Heydon E, et al. Adherence to cardiovascular therapy: a meta-analysis of prevalence and clinical consequences. Eur Heart J. 2013;34(38):2940-2948.

6. Lennon O, Galvin R, Smith K, Doody C, Blake C. Lifestyle interventions for secondary disease prevention in stroke and transient ischaemic attack: a systematic review. Eur J Prev Cardiol. 2014;21(8):1026-1039.

7. Müller-Nordhorn J, Nolte CH, Rossnagel K, et al. Knowledge about risk factors for stroke: a population-based survey with 28,090 participants. Stroke. 2006;37(4):946-950.

8. Jones SP, Jenkinson AJ, Leathley MJ, Watkins CL. Stroke knowledge and awareness: an integrative review of the evidence. Age Ageing. 2010; 39(1):11-22.

9. Ellis C, Barley J, Grubaugh A. Poststroke knowledge and symptom awareness: a global issue for secondary stroke prevention. Cerebrovasc Dis. 2013;35(6):572-581.

10. MacLean S, Mulla S, Akl EA, et al. Patient values and preferences in decision making for antithrombotic therapy: a systematic review. Chest. 2012;141(2 Suppl):e1S-e23S.

11. Man-Son-Hing M, Gage BF, Montgomery AA, et al. Preference-based antithrombotic therapy in atrial fibrillation: implications for clinical decision making. Med Decis Making. 2005;25(5):548-559.

12. Hafsteinsdóttir TB, Vergunst M, Lindeman E, Schuurmans M. Educational needs of patients with a stroke and their caregivers: a systematic review of the literature. Patient Educ Couns. 2011;85(1):14-25.
13. McKevitt C, Fudge N, Redfern J, et al. Self-reported long-term needs after stroke. Stroke. 2011;42(5):1398-1403.

14. Nieuwlaat R, Wilczynski N, Navarro T, et al. Interventions for enhancing medication adherence. Cochrane Database Syst Rev. 2014;11: CD000011.

15. Oshima Lee E, Emanuel EJ. Shared decision making to improve care and reduce costs. N Engl J Med. 2013;368(1):6-8.

16. Lenz M, Buhse S, Kasper J, Kupfer R, Richter T, Mühlhauser I. Decision aids for patients. Dtsch Arztebl Int. 2012;109(22-23):401-408.

17. Bunge M, Mühlhauser I, Steckelberg A. What constitutes evidencebased patient information? Overview of discussed criteria. Patient Educ Couns. 2010;78(3):316-328.

18. Heesen C, Kasper J, Sega J, Köpke S, Mühlhauser I. Decisional role preferences, risk knowledge and information interests in patients with multiple sclerosis. Mult Scler. 2004;10(6):643-650.

19. Roebers S, Razum O, Kutschmann M, Wagner M. Entwicklung und Evaluation einer deutschen Version des Fragebogens Stroke Action Test (STAT) zur Ermittlung der Kenntnisse über das richtige Verhalten bei einzelnen Schlaganfallsymptomen [Development and evaluation of a German version of the Questionnaire Stroke Action Test (STAT) to assess knowledge of the correct response to individual stroke symptoms]. Aktuel Neurol. 2008;35(7):334-339. German.

20. Schwartz LM, Woloshin S, Welch HG. Can patients interpret health information? An assessment of the medical data interpretation test. Med Decis Making. 2005;25(3):290-300.

21. Degner LF, Kristjanson LJ, Bowman D, et al. Information needs and decisional preferences in women with breast cancer. JAMA. 1997; 277(18):1485-1492.

22. Hickey A, Holly D, McGee H, Conroy R, Shelley E. Knowledge of stroke risk factors and warning signs in Ireland: development and application of the Stroke Awareness Questionnaire (SAQ). Int J Stroke. 2012;7(4):298-306.

23. Maruthappu M, Shalhoub J, Thapar A, Jayasooriya G, Franklin IJ, Davies AH. The patients' perspective of carotid endarterectomy. Vasc Endovascular Surg. 2010;44(7):529-534.

24. Lambert C, Vinson S, Shofer F, Brice J. The relationship between knowledge and risk for heart attack and stroke. J Stroke Cerebrovasc Dis. 2013;22(7):996-1001.

25. Carroll C, Hobart J, Fox C, Teare L, Gibson J. Stroke in Devon: knowledge was good, but action was poor. J Neurol Neurosurg Psychiatry. 2004;75(4):567-571.

26. Wiszniewska M, Głuszkiewicz M, Kobayashi A, et al. Knowledge of risk factors and stroke symptoms among nonstroke patients. Eur Neurol. 2012;67(4):220-225.

27. Koenig KL, Whyte EM, Munin MC, et al. Stroke-related knowledge and health behaviors among poststroke patients in inpatient rehabilitation. Arch Phys Med Rehabil. 2007;88(9):1214-1216.

28. Schneider AT, Pancioli AM, Khoury JC, et al. Trends in community knowledge of the warning signs and risk factors for stroke. JAMA. 2003;289(3):343-346.

29. Eames S, Hoffmann T, Worrall L, Read S, Wong A. Randomised controlled trial of an education and support package for stroke patients and their carers. BMJ Open. 2013;3(5): pii: e002538.

30. Heesen C, Kleiter I, Nguyen F, et al. Risk perception in natalizumabtreated multiple sclerosis patients and their neurologists. Mult Scler. 2010;16(12):1507-1512.

31. Gattellari M, Leung DY, Ukoumunne OC, Zwar N, Grimshaw J, Worthington JM. Study protocol: the DESPATCH study: delivering stroke prevention for patients with atrial fibrillation - a cluster randomised controlled trial in primary healthcare. Implement Sci. 2011;6:48.

32. Köpke S, Kern S, Ziemssen T, et al. Evidence-based patient information programme in early multiple sclerosis: a randomised controlled trial. J Neurol Neurosurg Psychiatry. 2014;85(4):411-418. 


\section{Supplementary materials}

Table SI Reaction on warning signs (patient subgroup $n=96$ )

\begin{tabular}{lllll}
\hline Assumed action & Call an ambulance & Visit general practitioner & Notify relatives & Wait \\
\hline Symptom & & & $7(7 \%)$ & 0 \\
Hemiparesis and aphasia & $86(91 \%)$ & $2(2 \%)$ & $1(3 \%)$ & $4(12 \%)$ \\
Aphasia & $22(69 \%)$ & $5(16 \%)$ & $6(6 \%)$ & $5(5 \%)$ \\
Paresthesia & $63(66 \%)$ & $22(23 \%)$ & $3(3 \%)$ & $3(3 \%)$ \\
Dizziness, nausea, vomiting & $67(70 \%)$ & $25(26 \%)$ & $2(2 \%)$ & $5(5 \%)$ \\
Loss of vision in one eye & $45(47 \%)$ & $43(45 \%)$ & $5(5 \%)$ & $2(2 \%)$ \\
Severe headache & $62(66 \%)$ & $57(60 \%)$ & $2(2 \%)$ & $28(29 \%)$ \\
Known headache & $6(6 \%)$ & $10(11 \%)$ & $2(2 \%)$ & $8(1 \%)$ \\
Chest pain & $82(86 \%)$ & $67(72 \%)$ & & $8 \%)$ \\
Abdominal pain and nausea & $16(17 \%)$ & &
\end{tabular}

Notes: $96 \%$ completed the questionnaire. $n=$ number of responses $(\%)$.

\section{General questions about stroke}

In the following, we want to ask you some general questions about stroke. In case you are not sure about the answer, try to reply as best as possible.

(Please choose only one answer per row)

\begin{tabular}{|c|c|c|c|}
\hline & Correct & False & Do not know \\
\hline An acute stroke can present by sudden visual loss. & [ ] & [ ] & [ ] \\
\hline $\begin{array}{l}\text { In case of mild stroke symptoms (for example, sensibility loss of one } \\
\text { arm or leg), it is adequate to present to the general practitioner next day. }\end{array}$ & [ ] & [ ] & [ ] \\
\hline A stroke can be caused by a cerebral arterial vessel occlusion. & [ ] & [ ] & [ ] \\
\hline A stroke can be caused by a cerebral bleeding. & [ ] & [ ] & [ ] \\
\hline $\begin{array}{l}\text { Antidiabetic medications lower blood glucose level and decrease the } \\
\text { long-term stroke risk. }\end{array}$ & [ ] & [ ] & [ ] \\
\hline Cardiac arrhythmias are an important cause of stroke. & [ ] & [ ] & [ ] \\
\hline
\end{tabular}

Stroke risk knowledge

(Please choose only one answer per row)

\begin{tabular}{|c|c|c|c|c|}
\hline & $\begin{array}{l}\text { From } \\
120 / 80\end{array}$ & $\begin{array}{l}\text { From } \\
140 / 90\end{array}$ & $\begin{array}{l}\text { From } \\
150 / 95\end{array}$ & $\begin{array}{l}\text { From } \\
160 / 100\end{array}$ \\
\hline \multirow{2}{*}{$\begin{array}{l}\text { Arterial hypertension increases the risk of stroke. Treatment with } \\
\text { antihypertensive medication reduces the risk of stroke. Which is the } \\
\text { lowest blood pressure value }(\mathrm{mmHg}) \text { already considered hypertensive? }\end{array}$} & [ ] & [ ] & [ ] & [ ] \\
\hline & $>90$ & $\sim 60$ & $\sim 30$ & $>10$ \\
\hline \multirow{2}{*}{$\begin{array}{l}100 \text { patient take aspirin after suffering a stroke. In how many cases, } \\
\text { a secondary prevention of stroke can be reached? }\end{array}$} & [] & [ ] & [ ] & [ ] \\
\hline & Cancer & Stroke & \multicolumn{2}{|c|}{ Both risk } \\
\hline $\begin{array}{l}\text { Mrs Meyer is informed by her physician that her risk dying of cancer is } \\
1 \text { to } 296 \text {. Her risk dying after stroke is } 1 \text { to } 407 \text {. Which risk is higher? }\end{array}$ & {[]} & [] & \multicolumn{2}{|c|}{ [ ] } \\
\hline Decision-making & & & & \\
\hline
\end{tabular}

There are different kinds of decision making regarding the prevention of stroke.

(Please choose which form you would prefer:)

I want to decide for myself, which kind of treatment I receive.

I want to decide for myself, which kind of treatment I receive, after I took the opinion of my physician into account.

I want to decide together with my physician, which kind of treatment would be the best for me.

I want my physician to decide, which kind of treatment would be the best for me, but taking my opinion into account.

How high would you self-estimate your knowledge about stroke prevention?

(Please mark the line)

\begin{tabular}{lllllllllll}
\hline $\begin{array}{l}\text { I have no } \\
\text { knowledge }\end{array}$ & 1 & 2 & 3 & 4 & 5 & 6 & 7 & 8 & 9 & 10 \\
\hline
\end{tabular}

Figure SI Questionnaire. 
Patient Preference and Adherence

Dovepress

\section{Publish your work in this journal}

Patient Preference and Adherence is an international, peer-reviewed, open access journal that focuses on the growing importance of patient preference and adherence throughout the therapeutic continuum. Patient satisfaction, acceptability, quality of life, compliance, persistence and their role in developing new therapeutic modalities and compounds to optimize

clinical outcomes for existing disease states are major areas of interest for the journal. This journal has been accepted for indexing on PubMed Central. The manuscript management system is completely online and includes a very quick and fair peer-review system, which is all easy to use. Visit http://www. dovepress.com/testimonials.php to read real quotes from published authors.

Submit your manuscript here: http://www.dovepress.com/patient-preference-and-adherence-journal 